\title{
Synthesis and Utility of 2,2-Dimethyl-2H-pyrans: Dienes for Sequential Diels-Alder/Retro-Diels-Alder Reactions
}

\author{
David Tejedor, ${ }^{*}$ Abián Díaz-Díaz, ${ }^{\dagger}$ Raquel Diana-Rivero, ${ }^{\dagger}$ Samuel Delgado-Hernández, ${ }^{\dagger}$ \\ and Fernando García-Tellado*(0)
}

Instituto de Productos Naturales y Agrobiología, Consejo Superior de Investigaciones Científicas, Avda. Astrofísico Francisco Sánchez 3, 38206 La Laguna, Canary Islands, Spain

\section{Supporting Information}

ABSTRACT: The practical use of 2,2-dimethyl- $2 H$-pyrans as electron-rich dienes in sequential Diels-Alder/retro-Diels-Alder $(\mathrm{DA} / \mathrm{rDA})$ domino processes to generate aromatic platforms has been demonstrated. Different polysubstituted alkyl 2-naphthoates have been synthesized by the $\mathrm{DA} / \mathrm{rDA}$ reaction of benzynes and 2,2-dimethyl- $2 \mathrm{H}$-pyrans. The use of other activated alkynes allows the access of substituted alkyl benzoate derivatives.

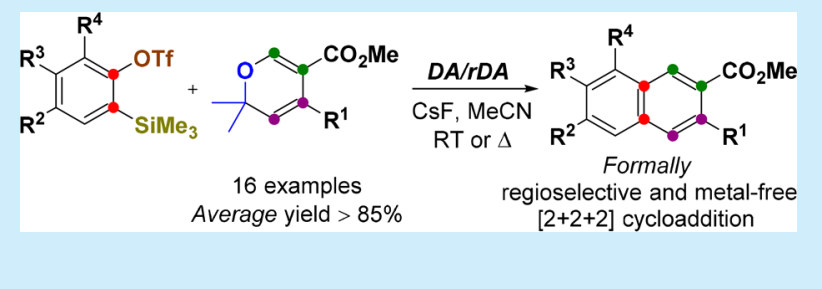

in the field of bioorthogonal ligation. ${ }^{2}$ Although the $\mathrm{DA} / \mathrm{rDAR}$ manifolds based on 1,2,4,5-tetrazines, ${ }^{1,2}$ triazines, ${ }^{3}$ and 1,2diazines ${ }^{4}$ have received much attention, those based on $2 \mathrm{H}$ pyran-2-ones ${ }^{5}$ have also found use in organic synthesis to a lesser extent (Scheme 1a), ${ }^{6}$ due to the harsher reaction conditions required, mainly when using alkenes as dienophiles. ${ }^{7,8}$ An important drawback associated with these dienyl platforms is the synthetic difficulty to introduce functional diversity in their structures. ${ }^{9} \mathrm{We}^{10}$ and others ${ }^{11}$ have recently shown that 2,2-disubstituted-2H-pyrans 1 are convenient dienes for Diels-Alder reactions. In contrast to simple $2 \mathrm{H}$ pyrans $(2 \mathrm{HP})$, which usually exist as an equilibrium mixture of monocycle and the linear 1-oxatriene (Scheme 1b), ${ }^{12}$ the 2,2disubstituted derivatives 1 constitute stable monocyclic entities amenable for isolation, storage, and handling. We envisioned that dienes based on the 2,2-dimethyl-2H-pyran unit, the most architecturally simple member of this series, could be suitable reactants for $\mathrm{DA} / \mathrm{rDAR}$ manifolds if the acetone extrusion from the intermediate DA adduct $\left(\mathrm{XY}=\mathrm{Me}_{2} \mathrm{CO}\right.$; Scheme 1a) was spontaneous and substrate independent. ${ }^{13}$ In terms of functional diversity, substituted members of the 2,2-dimethyl$2 \mathrm{H}$-pyran series (i.e., 3) would be easily accessible from the corresponding propargyl vinyl ethers 2 (PVEs) through the thermally driven all-pericyclic cascade reaction depicted in Scheme 1c. ${ }^{10}$ The pericyclic manifold would deliver the $2 \mathrm{HP}$ derivatives 3 endowed with a variable substituent at C-4 and a fixed ester group ( $Z$ in Scheme 1c) at C-5. Interestingly, the reactivity of these 2,2-dimethyl-2H-pyrans (electron-rich dienes) should be complementary to that shown by aza-dienes and $2 \mathrm{H}$-pyrones (electron-deficient dienes). We report herein the synthesis of these dienes and their use in domino DA/rDA manifolds designed to synthesize polysubstituted aromatic platforms.

Received: November 7, 2018

Published: December 11, 2018 
We began searching for the experimental conditions needed to transform PVE 2a into the corresponding $2 \mathrm{HP} 3 \mathrm{a}$, arriving at a set of optimized reaction conditions which entailed imidazole as catalyst $(10 \mathrm{~mol} \%)$, refluxing toluene as the reaction medium, and $48 \mathrm{~h}$ as the reaction time (Scheme 2).

Scheme 2. Exploring the Use of 2,2-Dimethyl-2H-pyrans as Dienes in DA/rDA Manifolds

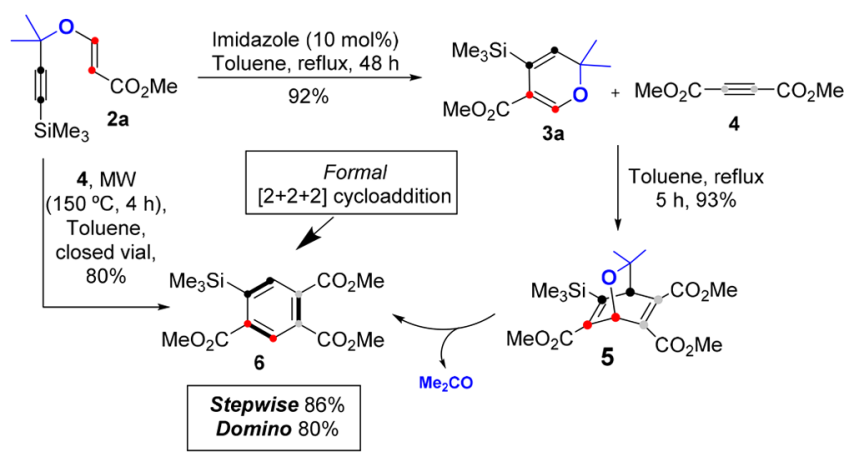

Under these conditions, 3 a could be obtained in $92 \%$ yield. ${ }^{14}$ We then continued exploring the behavior of $\mathbf{3 a}$ as a DielsAlder diene with dimethyl acetylenedicarboxylate (4) (Scheme 2 ). The use of a reactive, electron-poor alkyne as dienophile was expected to favor both the cycloaddition reaction (electronic matching) and the acetone extrusion (rDA, aromatization) from the bicyclic DA adduct intermediate 5 . The heating of $3 \mathrm{a}$ with 4 in toluene under reflux for $5 \mathrm{~h}$ delivered the 1,2,4-benzenetricarboxylate derivative $6^{15}$ in excellent yield (95\%). Due to the orthogonal reactivity of the starting PVE 2a and dienophile 4, the telescoping synthesis was carried out with excellent yield (80\%) (toluene, MW, 150 ${ }^{\circ} \mathrm{C}, 4 \mathrm{~h}$ ). Formally, the whole process can be considered a regioselective and metal-free $[2+2+2]$ cycloaddition reaction $^{16}$ of methyl propiolate, trimethylsilylacetylene, and dimethyl acetylenedicarboxylate. It should be noted that selective $[2+2+2]$ cycloadditions of three different alkynes remain challenging in current organic synthesis. ${ }^{16 \mathrm{~b}}$ On the other hand, the reaction of $3 a$ with $N$-benzylmaleimide (7) ( 1.5 equiv, toluene, reflux, $16 \mathrm{~h}$ ) delivered the corresponding DA adduct 8 in good yield (86\%) (eq 1). As was expected, ${ }^{19}$ the $\mathrm{rDA}$ reaction was not observed in this case because the acetone extrusion requires aromatization to proceed. Once the suitability of these dienes for $\mathrm{DA} / \mathrm{rDA}$ reactions was shown, we next explored their utility in the synthesis of fused aromatic polycycles, specifically, in the synthesis of substituted alkyl 2naphthoates, a valuable aromatic scaffold in material science. ${ }^{18}$ The classical chemical methods for synthesizing substituted naphthoic acids, including the Kolbe-Schmitt carboxylation of naphthols and the alkali fusion of sulfonaphthoic acids, require harsh reaction conditions, multistep processes, and environmentally harmful chemicals. ${ }^{19}$ In addition, they are accompanied by low regioselectivity, which ultimately translates to low yields.

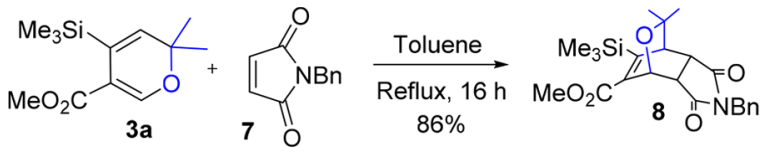

Recently, a gold-catalyzed cyclization of aromatic $\alpha$ hydroxyalkyl allenic esters was reported for accessing 2naphthoate motifs adorned with different hydroxylation patterns. ${ }^{20}$ The protocol imposes restrictive electronic requirements to the substituents adorning the final aromatic ring (electron-donating character). A more general and convenient route to these motifs relies on the DA reaction of in situ generated benzynes (highly reactive dienophiles) and rigid cisoid dienes such as furans, isobenzofurans, and cyclopentadienones among others (Scheme 3$).^{21}$ Both processes

Scheme 3. DA Reaction of Benzynes with Furans and Cyclopentadiones To Generate Naphthalene Derivatives

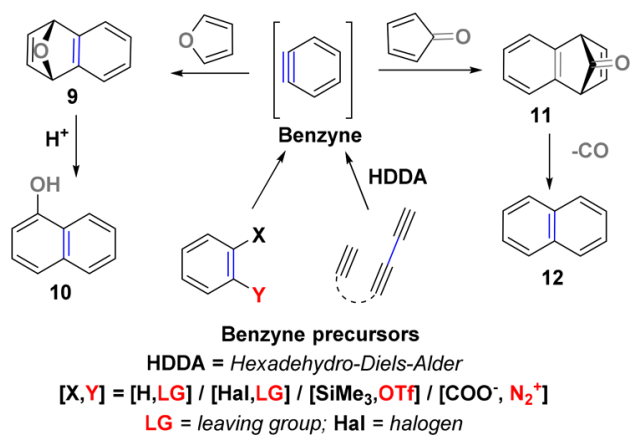

have been profusely explored ${ }^{22}$ for accessing complex naphthol derivatives (furans/isobenzofurans) or reduced naphthalene derivatives (cyclopentadienones). Whereas the use of furans as dienes requires a subsequent acid treatment of the DA adduct intermediate 9 to generate the naphthol motif 10, the in situ extrusion of $\mathrm{CO}$ from the DA adduct $\mathbf{1 1}$ directly affords the naphthalene scaffold 12. Curiously, and despite the advances realized in aryne chemistry, ${ }^{23}$ a few rigid dienes amenable to participate in $\mathrm{DA} / \mathrm{rDA}$ manifolds have been explored. This scarcity prompted us to explore the viability of our $\mathrm{DA} / \mathrm{rDA}$ manifold as a practical alternative and general protocol to gain access to these structural motifs (eq 2 in Scheme 5).

The viability of this protocol was established using the reaction of 3a with the benzyne precursor $13 \mathbf{a}$ and $\mathrm{CsF}$ as a model. After being stirred for $16 \mathrm{~h}$ at room temperature in acetonitrile, the reaction delivered the corresponding naphthoate derivative 14a in an excellent $91 \%$ yield. Prompted by this result, we explored the scope of the reaction using a set of synthesized 2,2-dimethyl-2H-pyrans 3 and the aryl trifluoromethanesulfonates 13a-f depicted in Scheme 4. In general, the reaction tolerated a wide range of substitution at the C-4 position of the pyranyl ring and the benzene ring of the aryne (Scheme 5, average yield: $85 \%$ ). The substitution at C-4 spanned from cyclic and acyclic alkyl chains $(14 \mathrm{c}$ and $14 \mathrm{e}-\mathrm{g}$ ) to alkenyl (14h), phenyl (14d), silyl $(\mathbf{1 4 a}, \mathbf{b})$, or bromide (14i). Although, in this last case, the yield decreased to a moderate $53 \%$, it still remains synthetically competitive and highlights the chemical versatility and smoothness of the protocol. A similar decrease in yield (52\%) was observed in the case of $14 \mathrm{~h}$, which incorporates a conjugated alkene in its structure, amenable for participating in other competitive processes with the benzyne. As anticipated, and due to the known high reactivity of benzynes, the nature of the substitution pattern in the benzyne precursors has a very small influence on the overall yield of the reaction. Thus, the reaction tolerated both electron-donating groups (OMe, $-\mathrm{OCH}_{2} \mathrm{O}$, alkyl) and electron-withdrawing groups (-F) on the aromatic ring. Interestingly, the monosubstituted benzyne precursor $13 \mathrm{~d}$ afforded naphthoate derivative $14 \mathrm{k}$ in $83 \%$ yield and a 96:4 ratio of regioisomers (the minor regioisomer is not 
Scheme 4. (a) Synthesis of 2,2-Dimethyl-2H-pyrans 3 from PVEs 2 and (b) Set of Benzyne Precursors 13 Used in This Study

a) Synthesis of 2,2-dimethyl-2H-pyrans used in this study<smiles>[R]C#CC(C)(C)O/C=C/C(=O)OC</smiles><smiles>COC(=O)C1=COC(C)(C)C=C1C(=O)OC</smiles>

3a, $R=\operatorname{Me}(92 \%)$

$3 b, R=E t(82 \%)$

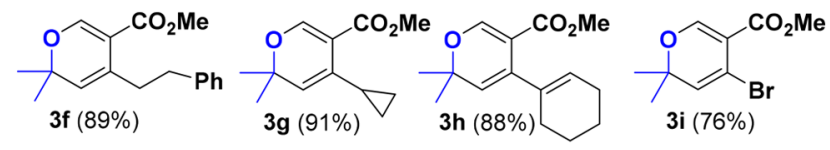

b) Aryl trifluoromethanesulfonates used in this study<smiles>CCOc1ccccc1S(C)(C)C</smiles><smiles>CCOc1cc2c(cc1[Se])OCO2</smiles><smiles>CCCOc1cc(OC)c(OC)cc1[AsH2]</smiles>

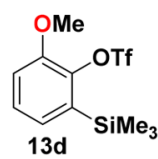<smiles>CCOc1cc(C)c(C)cc1Br</smiles>

Scheme 5. Domino Synthesis of Alkyl 2-Naphthoates 14 from Benzyne Precursors 13 and 2,2-Dimethyl-2H-pyrans $3^{a}$

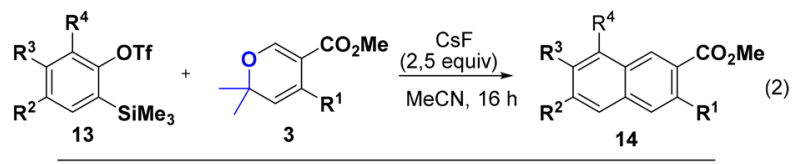

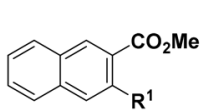

14a, $\mathbf{R}^{1}=\mathrm{Me}_{3} \mathrm{Si}(91 \%)^{\mathrm{b}}$

14b, $R^{1}=\mathrm{Et}_{3} \mathrm{Si}(94 \%)^{\mathrm{b}}$

$14 \mathrm{c}, \mathrm{R}^{1}=\mathrm{Me}(86 \%)$

14d, $R^{1}=P h(88 \%)^{\mathrm{C}}$

$14 \mathrm{e}, \mathrm{R}^{1}=\mathrm{n}-\mathrm{Bu}(92 \%)$

14f, $\mathbf{R}^{1}=\mathrm{CH}_{2} \mathrm{CH}_{2} \mathrm{Ph}(93 \%)$

$14 \mathrm{~g}, \mathrm{R}^{1}=\mathrm{CyPr}(98 \%)$

$14 \mathrm{~h}, \mathrm{R}^{1}=\mathrm{C}_{6} \mathrm{H}_{9}(52 \%)$

$14 i, R^{1}=\operatorname{Br}(53 \%)$

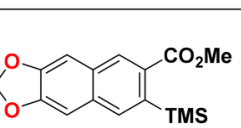

$14 \mathrm{j}(78 \%)$

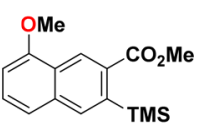

$14 \mathrm{k}(83 \%)(96: 4)^{\mathrm{c}}$
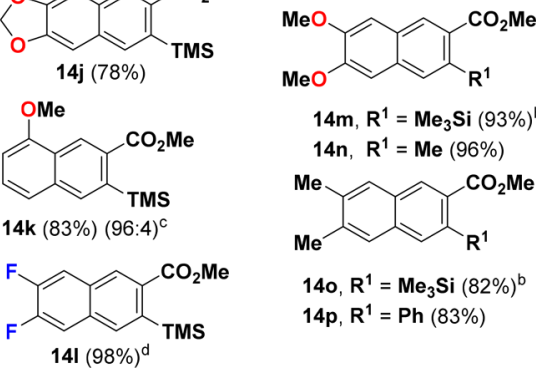

$14 \mathrm{~m}, \mathbf{R}^{1}=\mathrm{Me}_{3} \mathrm{Si}(93 \%)^{\mathrm{b}}$ $14 n, R^{1}=$ Me (96\%)

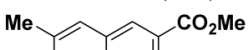<smiles>[R1]c1cc2c(cc1CC)=CC1=CC(=C(C)C=2)CC1</smiles>

14o, $\mathbf{R}^{1}=\mathrm{Me}_{3} \mathrm{Si}(82 \%)^{\mathrm{b}}$ $14 p, R^{1}=P h(83 \%)$
${ }^{a}$ General procedure: 2,2-dimethyl-2H-pyrane 3 (1 equiv), aryl trifluoromethanesulfonate 13 ( 1.25 equiv), $\mathrm{CsF}$ ( 2.5 equiv), $\mathrm{MeCN}$ $(0.06 \mathrm{M}), \mathrm{rt}, 16 \mathrm{~h} .{ }^{b}$ Reflux. ${ }^{c}$ Regioisomeric ratio. ${ }^{d} 13$ (1.5 equiv), CsF (3 equiv).

shown). The observed regioselectivity can be explained mainly from the polar effect of the methoxy substituent on the aryne (distortion effect) and the polarization of the diene system. This is in full accord with the regioselectivity predicted by the distortion model introduced by Houk. ${ }^{24}$

In summary, we have shown that 2,2-dimethyl- $2 \mathrm{H}$-pyrans 3 can participate in $\mathrm{DA} / \mathrm{rDA}$ domino processes as the electronrich diene component to generate polysubstituted aromatic platforms. Specifically, we have shown that the use of dimetyl acetylenedicarboxylate 4 as dienophile generates trimethyl 1,2,4-benzenetricarboxylate building blocks 6 armed with a substituent at the $\mathrm{C}-5$ position of the ring (diversity point).
The chemical outcome of this manifold formally corresponds with that of a regioselective $[2+2+2]$ cycloaddition reaction of methyl propiolate, trimethylsilylacetylene, and dimethyl acetylenedicarboxylate. Moreover, we have shown that the reaction of these 2,2-dimethyl-2H-pyrans 3 with differently substituted benzyne precursors $\mathbf{1 3}$ generates the corresponding substituted alkyl-2-naphthoate derivatives 14 in excellent yields and regioselectivity (asymmetrically substituted benzyne). We believe that these electron-rich dienes will find practical use in organic synthesis, mainly in the domino synthesis of aromatic platforms hitherto inaccessible by current $\mathrm{DA} / \mathrm{rDA}$ reactions.

\section{ASSOCIATED CONTENT}

\section{Supporting Information}

The Supporting Information is available free of charge on the ACS Publications website at DOI: 10.1021/acs.orglett.8b03558.

Detailed optimization, experimental procedures and spectroscopic data for all new compounds (PDF)

\section{AUTHOR INFORMATION}

\section{Corresponding Authors}

*E-mail: dtejedor@ipna.csic.es.

*E-mail: fgarcia@ipna.csic.es.

ORCID

Fernando García-Tellado: 0000-0001-6470-6289

Notes

The authors declare no competing financial interest.

${ }^{\dagger}$ Doctoral and Postgraduate School, University of La Laguna.

\section{ACKNOWLEDGMENTS}

The authors thank the Spanish Ministry of Economy and Competitiveness (MINECO), the European Regional Development Funds (ERDF) (CTQ2015-63894-P), and the Canarian Agency for Research, Innovation and the Information Society (ACIISI) (ProID2017010019 ACIISI/FEDER, EU) for financial support. S.D.H. thanks La Laguna University and Cajasiete for a predoctoral contract. We thank technician Ms. Estefania Gámez (IPNA-CSIC) for her experimental assistance.

\section{DEDICATION}

Dedicated to Professor Victor S. Martin on the occasion of his 65th birthday.

\section{REFERENCES}

(1) (a) Foster, R. A. A.; Willis, M. C. Chem. Soc. Rev. 2013, 42, 63. (b) Boger, D. L. Chem. Rev. 1986, 86, 781. (c) Rickborn, B. Org. React. 1998, 53, 223.

(2) (a) Wu, H.; Devaraj, N. K. A. Acc. Chem. Res. 2018, 51, 1249. (b) Oliveira, B. L.; Guo, Z.; Bernardes, G. J. L. Chem. Soc. Rev. 2017, 46, 4895.

(3) For selected examples, see: (a) Jouha, J.; et al. Org. Lett. 2017, 19, 4770. (b) Anderson, E. D.; Duerfeldt, A. S.; Zhu, K.; Glinkerman, C. M.; Boger, D. L. Org. Lett. 2014, 16, 5084 and refs cited therein .

(c) Anderson, E. D.; Boger, D. L. Org. Lett. 2011, 13, 2492.

(d) Anderson, E. D.; Boger, D. L. J. Am. Chem. Soc. 2011, 133, 12285.

(e) Raw, S. A.; Taylor, R. J. K. J. Am. Chem. Soc. 2004, 126, 12260.

(4) For selected examples, see: (a) Sumaria, C. S.; Tuerkmen, Y. E.; Rawal, V. H. Org. Lett. 2014, 16, 3236. (b) Kessler, S. N.; Wegner, H. A. Org. Lett. 2010, 12, 4062. (c) Boger, D. L.; Coleman, R. S. J. Org. Chem. 1984, 49, 2240. 
(5) Goel, A.; Ram, V. J. Tetrahedron 2009, 65, 7865.

(6) (a) Jiang, X.; Wang, R. Chem. Rev. 2013, 113, 5515. (b) For recent selected examples, see: Guney, T.; Lee, J. J.; Kraus, G. A. Org. Lett. 2014, 16, 1124. (c) Smith, M. W.; Snyder, S. A. J. Am. Chem. Soc. 2013, 135, 12964. (d) Vinader, V.; Haji-Abdullahi, M. H.; Patterson, L. H.; Afarinkia, K. PLoS One 2013, 8, e82111. (e) Kraus, G. A.; Riley, S.; Cordes, T. Green Chem. 2011, 13, 2734. (f) Afarinkia, K.; Abdullahi, M. H.; Scowen, I. Org. Lett. 2010, 12, 5564. (g) Birch, A. M.; Birtles, S.; Buckett, L. K.; Kemmitt, P. D.; Smith, G. J.; Smith, T. J. D.; Turnbull, A. V.; Wang, S. J.Y. J. Med. Chem. 2009, 52, 1558. (h) Baran, P. S.; Burns, N. Z. J. Am. Chem. Soc. 2006, 128, 3908.

(7) (a) Afarinkia, K.; Vinader, V.; Nelson, T. D.; Posner, G. H. Tetrahedron 1992, 48, 9111. (b) For the $\mathrm{CO}_{2}$ extrusion conditions, see: Abdullahi, M. H.; Thompson, L. M.; Bearpark, M. J.; Vinader, V.; Afarinkia, K. Tetrahedron 2016, 72, 6021.

(8) (a) For less-developed sulfone-based dienic systems, see: Gaitzsch, J.; Rogachev, V.; Zahel, M.; Metz, P. Synthesis 2014, 46, 531.

(b) For 2-pyridone-based manifolds, see ref 5 .

(9) (a) For a discussion about $2 \mathrm{H}$-pyranones, see ref 3. (b) For selected examples, see: Huang, J.; Li, L.; Chen, H.; Xiao, T.; He, Y.; Zhou, L. J. Org. Chem. 2017, 82, 9204. (c) Yeh, P.-P.; Daniels, D. S. B.; Cordes, D. B.; Slawin, A. M. Z.; Smith, A. D. Org. Lett. 2014, 16, 964. (d) For a discussion about tetrazines, see ref 1.

(10) Tejedor, D.; Delgado-Hernández, S.; Peyrac, J.; GonzálezPlatas, J.; García-Tellado, F. Chem. - Eur. J. 2017, 23, 10048.

(11) For selected examples, see: (a) Xie, P.; Yang, J.; Zheng, J.; Huang, Y. Eur. J. Org. Chem. 2014, 2014, 1189. (b) Iyer, K.; Rainier, J. D. Sci. Synth 2008, 37, 555. (c) Malerich, J. P.; Maimone, T. J.; Elliott, G. I.; Trauner, D. J. Am. Chem. Soc. 2005, 127, 6276. (d) Malerich, J. P.; Trauner, D. J. Am. Chem. Soc. 2003, 125, 9554.

(12) For a discussion of this issue, see: (a) Menz, H.; Kirsch, S. F. Org. Lett. 2006, 8, 4795. (b) Li, C.; Johnson, R. P.; Porco, J. J. Am. Chem. Soc. 2003, 125, 5095.

(13) The reaction of 2,2,4,6-tetramethylpyran and dimethyl acetylenedicarboxylate has been reported to generate acetone and dimethyl 3,4-dimethylphthalate in undetermined amounts, along with other products from decomposition of the starting pyran. Hussman, G.; Wulff, W. D.; Barton, T. J. J. Am. Chem. Soc. 1983, 105, 1263.

(14) The efficiency of the propargyl Claisen rearrangement of PVEs is facilitated by the degree of substitution on the PVE: higher substitution leads to lower temperatures and higher efficiencies. Tejedor, D.; Méndez-Abt, G.; Cotos, G.; García-Tellado, F. Chem. Soc. Rev. 2013, 42, 458.

(15) For selected recent syntheses of 1,2,4-benzenetricarboxylate derivatives via metal-catalyzed $[2+2+2]$ cycloadditions, see: (a) Brenna, D.; Villa, M.; Gieshoff, T. N.; Fischer, F.; Hapke, M.; Jacobi von Wangelin, A. Angew. Chem., Int. Ed. 2017, 56, 8451. (b) Rodrigo, S. K.; Powell, I. V.; Coleman, M. G.; Krause, J. A.; Guan, H. Org. Biomol. Chem. 2013, 11, 7653. (c) Tanaka, K.; Toyoda, K.; Wada, A.; Shirasaka, K.; Hirano, M. Chem. - Eur. J. 2005, 11, 1145. (d) Takeuchi, R.; Nakaya, Y. Org. Lett. 2003, 5, 3659.

(16) (a) For a review of metal-free formal $[2+2+2]$ cycloadditions, see: Hapke, M. Tetrahedron Lett. 2016, 57, 5719.

(b) For a recent discussion on this topic, see: Tamizmani, M.; Sivasankar, C. J. Organomet. Chem. 2017, 845, 82.

(17) Huffman, K. R.; Ullman, E. F. J. Am. Chem. Soc. 1967, 89, 5629.

(18) For selected examples, see: (a) Kobayashi, N.; et al. J. Lumin. 2018, 200, 19. (b) Xu, F.; Hershey, K. W.; Holmes, R. J.; Hoye, T. R. J. Am. Chem. Soc. 2016, 138, 12739. (c) Xu, H.-X.; et al. J. Org. Chem. 2012, 77, 1685. (d) Park, J. K.; Lee, K. H.; Park, J. S.; Seo, J. H.; Kim, Y. K.; Yoon, S. S. Mol. Cryst. Liq. Cryst. 2010, 531, 55. (e) Katagiri, K.; et al. J. Mol. Struct. 2008, 891, 346. (f) Hine, P. J.; Astruc, A.; Ward, I. M. J. Appl. Polym. Sci. 2004, 93, 796. (g) Tung, C. H.; Wu, L.-Z.; Zhang, L.-P.; Chen, B. Acc. Chem. Res. 2003, 36, 39.

(19) (a) Lindsey, A. S.; Jeskey, H. Chem. Rev. 1957, 57, 583.

(b) Butler, C.; Royle, F. A. J. Chem. Soc., Trans. 1923, 123, 1649.

(c) Adcock, W.; Wells, P. R. Aust. J. Chem. 1965, 18, 1351. (d) Cason,

J. J. Am. Chem. Soc. 1941, 63, 828.

(20) Park, C.; Lee, P. H. Org. Lett. 2008, 10, 3359.
(21) Sanz, R.; Suárez, A. The Chemistry of Arynes: An overview. In Arene Chemistry: Reaction Mechanisms and Methods for Aromatic Compounds; Mortier, J., Ed.; John Wiley \& Sons, Inc.: Hoboken, NJ, 2015; pp 3001-336.

(22) There are many examples in the literature. For a selection of recent examples, see: (a) Xiao, X.; Hoye, T. R. Nat. Chem. 2018, 10, 838. (b) Prévost, S.; Dezaire, A.; Escargueil, A. J. Org. Chem. 2018, 83, 4871. (c) Xu, F.; Xiao, X.; Hoye, T. R. J. Am. Chem. Soc. 2017, 139, 8400. (d) Diamond, O. J.; Marder, T. B. Org. Chem. Front. 2017, 4, 891. (e) Pozo, I.; Cobas, A.; Peña, D.; Guitián, E.; Pérez, D. Chem. Commun. 2016, 52, 5534. (f) Mannes, P. Z.; Onyango, E. O.; Gribble, G. W. J. Org. Chem. 2015, 80, 11189. (g) Criado, A.; Vilas-Varela, M.; Cobas, A.; Pérez, D.; Peña, D.; Guitián, E. J. Org. Chem. 2013, 78, 12637. (h) Tadross, P. M.; Stoltz, B. M. Chem. Rev. 2012, 112, 3550. (i) Criado, A.; Peña, D.; Cobas, A.; Guitián, E. Chem. - Eur. J. 2010, 16, 9736.

(23) For selected reviews, see: (a) Takikawa, H.; Nishii, A.; Sakai, T.; Suzuki, K. Chem. Soc. Rev. 2018, 47, 8030. (b) Yoshida, S.; Hosoya, T. Chem. Lett. 2015, 44, 1450. (c) Hoye, T. R.; Baire, B.; Niu, D.; Willoughby, P. H.; Woods, B. P. Nature 2012, 490, 208. (d) Gampe, C. M.; Carreira, E. M. Angew. Chem., Int. Ed. 2012, 51, 3766. (e) Bhunia, A.; Yetra, S. R.; Biju, A. T. Chem. Soc. Rev. 2012, 41, 3140.

(24) Medina, J. M.; Mackey, J. L.; Garg, N. K.; Houk, K. N. J. Am. Chem. Soc. 2014, 136, 15798 and refs cited therein . 